\title{
EDITORIAL
}

\section{Tax on saturated fat-does it work?}

\author{
European Journal of Clinical Nutrition (2016) 70, 867-868; \\ doi:10.1038/ejcn.2016.110
}

Unhealthy diet is an important modifiable risk factor for diseases as obesity, type 2 diabetes and cardiovascular diseases (CVDs), and changes to a more healthy diet has the potential to reduce the burden of diseases in society. Several attempts have been made to change the dietary habits of the population ranging from campaigns over general health check $^{1,2}$ to various forms of legislation and societal regulations. ${ }^{3}$ Denmark introduced a tax on all products containing more than $2.3 \mathrm{~g}$ per $100 \mathrm{~g}$ saturated fat in October 2011, but the tax was already abolished in January 2013. In a recent volume of Eur J Clin Nutr ${ }^{4}$ it was shown that intake of saturated fat in the Danish population was reduced by $4 \%$ during the period of the fat tax. This is quite different from an initial analyses performed by the same group, ${ }^{5}$ where they found a reduction of saturated fat on $10-15 \%$; both calculations were based on data from a national household survey on daily purchases. The latest finding, showing a small reduction, is comparable with findings from a study using national retail outlet data on the sale of twelve foodstuff categories targeted by the fat tax showing a reduction of $3.8 \%$ of saturated fat and $3.2 \%$ of dietary cholesterol. ${ }^{6}$

The studies have some disagreement on the estimated effect on CVD. Using various algorithms one study showed ${ }^{6}$ either an increase $(0.2 \%)$ or a decrease $(0.3 \%)$ in CVD. In these calculations the potential negative effect of the simultaneous reduction in, for example, polyunsaturated fat (3.6\%) was taken into account. Smed et al. ${ }^{4}$ estimated a decrease in CVD of $0.4 \%$. These calculations are speculative, as both studies ${ }^{4,6}$ found indication of an increase in intake of salty products that would increase the risk of CVD. It is therefore open to discussion whether there was any effect on health of the Danish fat tax at all. No effect on CVD is actually what could be expected, as the increase of the price of the food products containing saturated fat never came close to the $20 \%{ }^{6}$ which has been claimed to be a necessary increase, to obtain an effect. ${ }^{3}$

There are uncertainties in data used in both papers. Household survey data including information from families, who accept to join such a consumer panel, are probably not representative of the consumers in Denmark (even if it is aimed to ensure this), which lead to a high risk of selection bias. More representative data as data on sale are, therefore, needed. But also data on sale can be problematic; primarily because sales data is averaged across the entire population making it impossible, for example, to compare consumption by factors such as socio-economic groups and geographic area. Furthermore, in the analyses by Bødker et al. ${ }^{6}$ two discount chains were not included, as they were not in the national sales register. This could potentially draw the results towards even less reduction than reported, as it has been shown ${ }^{5}$ that there was a shift over time in demand from general supermarkets to low-price discount stores. Finally, both studies looked at foods purchased, not consumed, which means that we don't know whether the changes in sale lead to changes in consumption, although this is likely.

Another important issue is why the tax was introduced. Two studies have looked at the political process ${ }^{7,8}$ coming to the same result. The tax was primarily introduced to finance tax relieves, and only secondary for health purposes, which was underlined by the fact that it was not the Ministry of Health, but the Ministry of Finance that introduced the tax. Furthermore, the general picture discloses that public health researchers were not involved in the political process, which was the case for industry and trade associations. They used well known tactics to oppose and abolish the fat tax like threatening law suit, predicting welfare losses, casting doubt on evidence, diverting focus and requesting postponement. ${ }^{7,9}$ Finally, the tax was designed in a way that the tax paid for a product did not necessarily reflect the amount of saturated fat actually contained in the final product, making it easy for food industry and trade associations to ridicule it in the media.

There are several lessons to be learned from this Danish fat tax. First of all, the industry is very sensible to these kinds of regulations, as they want to secure their vested interests. Authorities should be aware of these interests and in the future collaborate with neutral institutes within public health in any new attempts to introduce taxation on unhealthy foods. Second, a tax on unhealthy foods should not be introduced to cover any tax reliefs. If the primary aim is a healthier population, the aim of the tax should be a reduction in intake of the food product in question, which will give less tax income for authorities. Finally, there is no doubt that price regulations on unhealthy foods is a potentially effective way to reduce the disease burden in society, but it should go through a much more thought-through process including a tax on various unhealthy food items, and at the same time lowering the taxes on healthy food items or taxes that take into account the overall nutritional profile of the food products. This should be done in collaboration between politicians, health authorities and public health researchers, whereas trade associations should have a minor (if any) role. As Director-General of WHO Margaret Chan said: 'Not one single country has managed to turn around its obesity epidemic in all age groups. This is not a failure of individual will-power. This is a failure of political will to take on big business.... When industry is involved in policymaking, rest assured that the most effective control measures will be downplayed or left out entirely. This, too, is well documented, and dangerous. ${ }^{10}$

Unfortunately, the story of the Danish tax on fat can be used to argue against regulation, which is a too hastened conclusion. The Danish fat tax was a failure due to poor planning.

\section{CONFLICT OF INTEREST}

The authors declare no conflict of interest.

T Jørgensen ${ }^{1,2,3}, \mathrm{C}$ Pisinger ${ }^{1}$ and $\mathrm{U}$ Toft $^{1}$

${ }^{1}$ Research Centre for Prevention and Health, Center for Health, Capital Region of Denmark, Glostrup, Denmark; ${ }^{2}$ Department of Public Health, Faculty of Health and Medical Science, University of Copenhagen, Copenhagen, Denmark and ${ }^{3}$ Faculty of Medicine, Aalborg University, Aalborg, Denmark E-mail: torben.joergensen@regionh.dk

\section{REFERENCES}

1 Krøgsboll LT, Jorgensen KJ, Gronhoj LC, Gotzsche PC. General health checks in adults for reducing morbidity and mortality from disease. Cochrane Database Syst Rev 2012; (10): CD009009. 
2 NHS health check implementation review and action plan. Available at: https:// www.gov.uk/government/publications/nhs-health-check-implementation-reviewand-action-plan (accessed 14 June 2016).

3 Mytton OT, Clarke D, Rayner M. Taxing unhealthy food and drinks to improve health. BMJ 2012; 344: e2931.

4 Smed S, Scarborough P, Rayner M, Jensen JD. The effects of the Danish saturated fat tax on food and nutrient intake and modelled health outcomes: an econometric and comparative risk assessment evaluation. Eur J Clin Nutr 2016; 70: 681-686.

5 Jensen JD, Smed S. The Danish tax on saturated fax - Short run effects on consumption, substitution patterns and consumer prices of fats. Food Policy 2013; 42: 18-31.
6 Bodker M, Pisinger C, Toft U, Jorgensen T. The Danish fat tax-effects on consumption patterns and risk of ischaemic heart disease. Prev Med 2015; 77: 200-203.

7 Bodker M, Pisinger C, Toft U, Jorgensen T. The rise and fall of the world's first fat tax. Health Policy 2015; 119: 737-742.

8 Vallgarda S, Holm L, Jensen JD. The Danish tax on saturated fat: why it did not survive. Eur J Clin Nutr 2015; 69: 223-226.

9 Jahiel RI. Corporation-induced diseases, upstream epidemiologic surveillance, and urban health. J Urban Health 2008; 85: 517-531.

10 Chan M. WHO Director-General addresses health promotion conference. Available at: http://www.who.int/dg/speeches/2013/health_promotion_20130610/en/ (accessed 14 June 2016). 